\title{
The "Tepid" China-Canada Relations: Characteristics and Reasons
}

\author{
Ting $\mathrm{Wu}$ \\ School of International Studies of Jinan University \\ Guangzhou, Guangdong, China \\ prettywuting@126.com
}

\author{
Xiaojian Liao \\ School of International Studies of Jinan University \\ Guangzhou, Guangdong, China \\ lxjhjh@163.com
}

\begin{abstract}
This paper aims at demonstrating and explaining why the China-Canada relations remain "tepid" for a long time. The article argues that the mismatch of state structure and social cognition is the main factor leading to the tepid state. The former is the objective outcome of states' heterogeneous; the latter is the subjective response to China's rising power. At present, structure and cognitive conflicts between China and Canada are still difficult to eliminate, the prospects of the bilateral relations will be not optimistic but keep tepid. China-Canada relations can be consolidated and developed in the future through deepening the interests-link, strengthening the mechanism construction and accumulating the social capital.
\end{abstract}

Keywords-China-Canada relations;
Characteristics; Reasons

\section{INTRODUCTION}

China-Canada relations have remained a tepid state, which shows that their cooperation is expanding at low progress, both in speed and depth. As frictions are non-fundamental and transient, they do not greatly affect both sides. Since the end of the Cold War, the relations between China and Canada have shown new characteristics which embody the changing pace and scope of the bilateral cooperation, the developing intensity and content of their frictions between these two countries. This paper tries to illustrate characteristics and reasons of this tepid state of China-Canada relations on the basis of their interaction over the past twenty years.

\section{CHARACTERISTIC OF THE “TEPID” STATE}

\section{A. Achievements of China-Canada cooperation}

After the 1990s, China-Canada relations have obtained some achievements, which reflect in four aspects including politics, economy, education and culture. Politically speaking, in 2005, the two countries have established Strategic Partnership. This was a milestone in the bilateral cooperation process. High-level visits and exchanges at other levels have gradually institutionalized, the exchanges at all levels have strengthened the political ties and mutual understanding between China and Canada. Besides, cooperation of justice and law enforcement has scored remarkable achievements. On the perspective of economy, the scale of trade and investment has growth significantly and the structure commodity has increasingly diversified as well. The sign of Investment Protection Agreement and the establishment of Renminbi Settlement Center in Toronto will facilitate the economic cooperation of China and Canada. Education is one of the strategic areas, in which the two governments play important roles. The exchange of students, international academic exchange and cooperation in running schools are the main forms of bilateral education cooperation. Furthermore, the cooperation in science, technology and cultural field between the two countries is deepening.

The driving force of China-Canada cooperation lies in the system, the state and the society dimensions. Firstly, the acceleration of economic globalization and the shift of economic power created a favorable international environment for bilateral cooperation. Secondly, the common preference of the economic interests of domestic actors as well as the growing demand of national economy promote the two governments to put the economic interests as the basic diplomatic principle. Thirdly, the deepening transnational relations and low politicization of foreign affairs create a space for Chinese Canadians to play an important part in promoting the development of bilateral relations.

\section{B. Representations of "Tepid" state}

Meanwhile, at present the depth of two countries' cooperation is unsatisfactory, and China-Canada relation remains in a lukewarm state. This can be shown in the following aspects:

\section{1) Cooperation degree is limited}

On the perspective of politics, since the 1990s, the two governments have signed a series of agreements while many of them have no substantial contents and exclusive framework. Taking "China-Canada strategic partnership" as an example, it is only a verbal contract between the leaders of the two countries. The leaders have not signed a formal cooperation document until now. Due to the lack of consensus and conceptions of cooperation between both sides, China-Canada relationship is vulnerable and subjected to accidental factors.

On the perspective of economy, the scale of bilateral trade and investment is small and the interdependence of their economy is weak. In 2015, Canada's total merchandise trade with China reached $\$ 67.1$ billion and accounted for $8.1 \%$ of Canada's world trade and less than $2 \%$ of China's world trade. Energy cooperation is a current important field. However, among the main trading partners of Canada, the proportion of Canada's energy exports to China is the lowest. In 2014, Canada's total energy exports to the world accounted for $27.1 \%$ of the whole exports, while the exports to China only accounted for 5.3\% ( $\$ 2.9$ billion), which is lower than the 
proportion of the USA(33.1\%), Korea(20.1\%) and Japan(10.5\%).[1]

In the terms of investment, in 2013, Canadian direct investment in China reached $\$ 0.5$ billion, accounting for $1.2 \%$ of Canada's global direct investment. Chinese direct investment in Canada reached $\$ 1$ billion and accounted for $0.9 \%$ of China's global direct investment. Hong Kong (\$62.8 billion), the United States (\$3.9 billion) and Australia (\$3.5 billion) are China's top three investment destinations. Chinese investment to Australia is three-fold of the amount of Canada's, accounting for $3.2 \%$ of China's global direct investment. [2]

On the perspective of education, China is the largest source of overseas students in Canada while Canada is not the first choice of Chinese students. Besides, Canada is facing fierce competition from other countries such as Australia. With the increasing tuition fees of Canadian college, the competitive advantage of Canada in international education market is gradually weakening as well. On the other hand, the number of Canadian students in China is not big, only 3.8 thousand persons in 2013.

\section{2) Frictions are accelerated}

There are also some frictions in the political, economic, cultural and other fields, which reflect in two aspects: the intensified inherent contradictions (trade friction, human rights disputes) and the constantly emerging frictions (information security, energy investment, the politicized of culture and education activities).

The growth in Canada's imports from China during the past two decades has outpaced the growth in the exports. As a result, Canada's trade deficit with China has increased from $\$ 1.1$ billion in 1993 to \$35.6billion in 2014. Canada's overall trade surplus was $\$ 301.4$ billion between 2006 to 2015. As the table below depicted, Ontario yielded the greatest trade deficit amongst all Canadian provinces and territories, almost nearly $\$ 29$ billion in 2014, representing $81 \%$ of Canada's merchandise trade deficit with China in the same year. [3] With the rising of trade deficit, Canadian trade protectionism on China is upgrading, and now China is the largest country with anti-dumping investigation.

TABLE I. 2014 Provincial Merchandise Trade With China

\begin{tabular}{|c|c|c|c|c|}
\hline \multicolumn{5}{|c|}{ (Millions of Canadian Dollars) } \\
\hline Province & Exports & Imports & $\begin{array}{l}\text { Total } \\
\text { trade } \\
\end{array}$ & Balance \\
\hline Ontario & 2101 & 30910 & 33011 & -28809 \\
\hline Quebec & 2542 & 8223 & 10765 & -5681 \\
\hline $\begin{array}{c}\text { British } \\
\text { Columbia } \\
\end{array}$ & 5922 & 9576 & 15498 & -3654 \\
\hline Alberta & 2629 & 2794 & 5423 & -165 \\
\hline Manitoba & 911 & 906 & 1817 & 5 \\
\hline Saskatchewan & 2557 & 219 & 2776 & 2338 \\
\hline others & 308 & 902 & 1210 & -594 \\
\hline
\end{tabular}

Human rights dispute is the greatest obstacle that hinders the deepening of China-Canada relations. After the Conservative government being in power in 2006, the Prime Minister and other offices kept on criticizing China's human rights situation and met Dalai, these provoked the disapproval of Chinese Government, an official from Chinese Foreign Ministry has ever announced that "it is a disgusting behavior”.[4]

Recently, the problems of information security, Canada's restriction of Chinese energy investment and Canadian boycott Chinese culture and education activities have emerged and hampered the cooperation between the two countries. In 2014, China-Canada relations once appeared nervous due to the event of Canadian Spy, and this is not solved until now. Besides, Canadians have a negative impression on China's language educational and cultural institution named Confucius Institute. A report of Canadian Security Intelligence Service argued that Confucius Institutes are closely linked to the Chinese Party-state, conducting “propaganda work”.[5]

\section{REASONS FOR THE “TEPID” STATE}

\section{A. Incompatible state structure}

Structural obstacle is a primary factor hindering the development of the China-Canada relations. The asymmetry in the geopolitical, economic and political structure of China and Canada adds to the complexity of Canadian politics, making it more difficult to deepen the bilateral relations.

\section{1) Geo-political structure}

On the geo-political structure, "living with Uncle (the United States)" is the fate of Canada, successive governments in Canada must put the relations with the United States on the priority. [6] Due to the influence of geographical environment, the degree of the involvement of political, economic and cultural exchange between the two countries is very high. Meanwhile, Canada's comprehensive strength has a very great distance from the United States, the population and economic scale of the United States is equivalent to more than 10 times of Canada. Thus, the every move of the United States will rasped Canada's nerves. Canada is extremely dependent on the USA in the area of economy, security and psychology. In other words, "when America sneezes, Canada will catch a cold”.

While due to the geopolitical factor and diplomatic tradition, China should pay more attention to neighboring countries and world superpowers. China has one of the largest numbers of neighboring countries in the world and quite a long coastline, which has made China's geo-strategic environment of unprecedented complexity. With the rising of China and the change of Asia-Pacific configuration, especially the east- turning of America's strategic attention, more and more uncertainties around China are emerging; China must pay more attention to its neighbors and the super power. As a middle power, Canada has no position in China's international strategy. 


\section{2) Economic structure}

On the Economic structure, the two countries are not each other's main market. In terms of Canada, America is the largest trade partner, Canadian merchandise exports to America accounts for more than $70 \%$ of Canada's global exports. Canada's energy, industrial and agricultural products are exported to the United States, including $99 \%$ of crude oil, natural gas and electricity every year.

However, China has a more diverse trade partners, the USA, EU and the countries of East Asia such as Japan and Korea are the main markets of Chinese commodities. Among them, The USA, EU and Hong Kong are the top three export markets of China, the total exports to the above three countries and regions accounted for $48.2 \%$ in 2014. [7]

As to the investment location, China (Hong Kong) and Canada (USA) are heavily dependent on a certain country/ region, their direct investment to the industry is different as well.

\section{3) Political structure}

As well know, China is a unitary state and Canada has a federal system of government with separation of powers, the differences in political and cultural areas make ideology become one of the criteria of Canadian China policy. Being affected of the Cold War mentality, on the one hand, Canada's foreign policy towards China is on the one hand committed to strengthen the economic ties with China as well as encourage social interactions and cultural exchanges. On the other hand, it keeps hostile to the socialist China, and provokes China on human rights and other values every now and then. Canada views the beat of China as a symbol of maintaining its diplomatic "moral standards". This thinking model makes Canada keep distance with China on political gesture, even if the engagement of economy.

The structural dislocation makes a red line between China and Canada, hampers the engagement of the two counties. As a result, China-Canada relation is always in a state of tepid in turn

\section{B. Misplaced social perception}

The difference of social perception is another factor responding to the "tepid" state, the change of Canadians' attitude to China has caused the transformation of Canadian China policy, and then affects the collaboration.

\section{1) Canada's vogue image in China}

Canada's image in China is positive. According to the survey about the Canada's image in China conducted by a Canadian-Chinese scholar Yuchao Zhu in 2011, a majority (60\%) of Chinese insisted that Canada was a friendly country and $79 \%$ respondents had a good impression of Canada. In terms of bilateral relations, 55\% of the respondents claimed that China and Canada had no national interests' conflict, and $74 \%$ also saw Canada-China relationship as generally good and $44 \%$ mentioned the current relationship as very good. A lot of Chinese thought Bethune was the most well-known Canadians in China (68\%). While human rights dispute (46\%), repatriation of criminal suspects (33\%) and Tibet issue (7\%) were mentioned as the most important obstacles in improving the bilateral relationship. [8] In the meantime, Chinese have a fussy about Canada; many Chinese only have an understanding of "maple leaf" or "a country in the north of the USA".

\section{2) Canadians' nagative cognition on China}

Canadians' negative cognation to the rising China is the biggest disruptive force that is responsible for the recent fluctuation of China-Canada relations. It is also the root of the friction between the two countries. According to the survey of PEW, 43\% Canadians seemed to be well disposed towards China in 2013, a sharp decrease of 15 percent over 2005.[9]

Canadians are frightened about the investment of Chinese state-owned enterprises especially. As the Fig.1 shows, Canadians who were interviewed by the Asia Pacific Foundation in 2015 are most worried about losing the control of their resource, the proportion accounted for $48 \%$. Canadians were afraid of the issues including poor labour standards, environment damage, corruption and security risk. More and more respondents object to strengthen the economic ties such as signing a Free Trade Agreement with China, on the contrary, they are apt to build a closer relationship with the "link-minded" partners. [10]

The conservatism of Canadian national consciousness forces the government to take the hardest line to China for the electoral interests. The disharmony of Canada results the incoherence of Canada's China policy. At present, the structure and cognitive conflicts are difficult to be eliminated in the short term, so the prospects of the bilateral relations will not be optimistic but remain tepid.

Idea has a constructive function to foreign affairs, the direct influence of conceptive factors is to underestimating the value of each other, and then influences the understanding and judgment of the cooperative potentiality and dividends. The difference of social cognition between the two countries has a negative effect on their cooperation, leading to a "tepid" state.

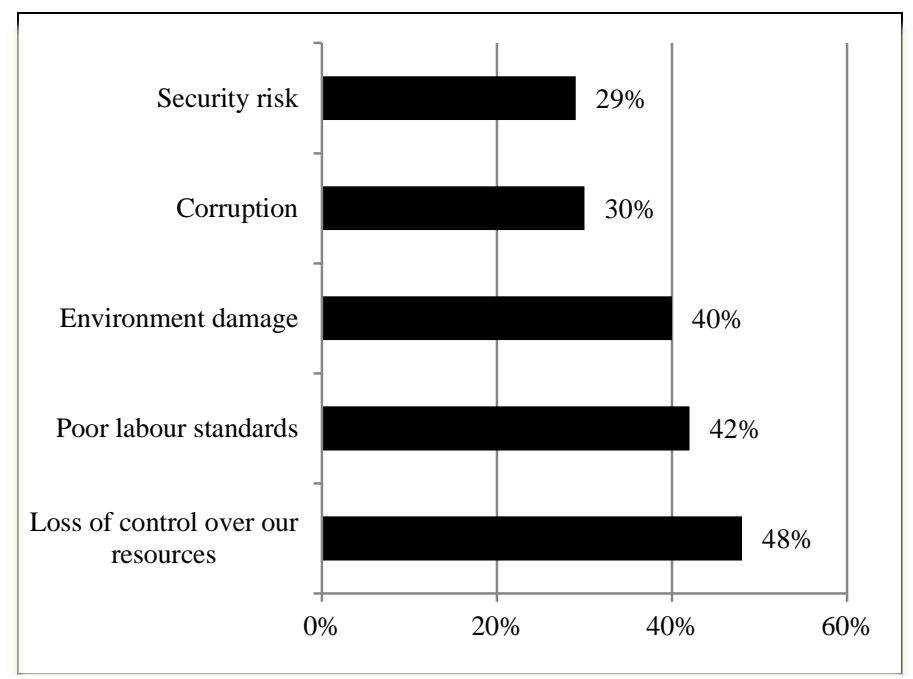

Fig. 1. Canadians associate investment from China with loss of control over resources 


\section{SUMMARY}

After the 1990s, China-Canada cooperation has steadily expanded in the breadth; this can be attributed to the interaction of the international and domestic structure. However, the depth of their cooperation is unsatisfactory; the degree of their cooperation in politics, economy and education is still limited. This can be ascribed to the mismatch of the state structure and social cognition. States' heterogeneous is the main factor hindering the development of collaboration and the change of Canadians' perception is the subjective response to the power change. Canadians' negative cognition to China is the biggest disruptive force that is responsible for the recent fluctuation of China-Canada relations and it is also the root of the friction between the two countries. At present, there are a lot of new factors of the international and nation environment which will promote or hinder the development of China-Canada relations at the same time. The structure and cognitive conflicts are difficult to be eliminated in the short term, and the prospects of the bilateral relations will not be optimistic but remain tepid. However, in the future, ChinaCanada relations can be consolidated and developed in the future through deepening the interests link, giving play to the complementary advantages, correct understanding of conflict areas, strengthening the mechanism construction, expanding the radius of trust and accumulating the social capital.

\section{ACKNOWLEDGMENT}

This research was financially supported by the National Social Science Foundation of China (Grant NO. 15AMZ012)

\section{REFERENCES}

[1] Industry Canada, trade data online, https://www.ic.gc.ca/eic/site/tdodcd.nsf/eng/home,accessed to 20 June 2016.

[2] Statistics Canada, http://www5.statcan.gc.ca/cansim/pick-choisir, accessed to 25 June 2015.

[3] Industry Canada, trade data online, https://www.ic.gc.ca/eic/site/tdodcd.nsf/eng/home,accessed to 20 June 2016.

[4] Nossal Kim Richard and Leah Sarson, About Face: Explaining Changes in Canada's China Policy, 2006 2012, Canadian Foreign Policy Journal, 2014, pp. 4.

[5] Canadian Security Intelligence Service, Confucius Institutes: Distinguishing the Political from the Culture, The Security Dimensions of An Influence China, Government of Canada, 2013, pp. 123.

[6] John W. Holmes, Life with Uncle: The Canadian-American Relationship, Toronto: University of Toronto Press, 1981.

[7] National Bureau of Statistics of China, http://www.stats.gov.cn/tjsj/zxfb/201502/t20150226_685799.html, accessed to 20 February 2016. (in Chinese)

[8] Yuchao Zhu, Making Sense of Canada's Public Image in China, Journal of American-East Asian Relations,2013, pp.273.

[9] PEW, America's Global Image Remains More Positive than China's, PEW Survey Center, July 18, 2013.

[10] Asia Pacific Foundation, National Opinion Poll: Canadian Views on Asia Investment, Vancouver: Asia Pacific Foundation of Canada, 2015, pp.18. 